\title{
The Influence of Digital Transformations on the Processes of Personal Identification in the Conditions of Social Systems Functioning
}

\author{
Anna Petrakova ${ }^{1}$, 'Tatyana Martseva ${ }^{2}$, Nadezhda Artemenko ${ }^{3}$, Yadviga Nebylova ${ }^{4}$ \\ ${ }^{1}$ Non-state Accredited Non-profit Private Educational Institution of Higher Education "Academy of Marketing and \\ Social and Information Technologies-IMSIT", Krasnodar, Russia \\ ${ }^{2}$ Federal State Educational Budgetary Institution of Higher Education "Financial University under the Government \\ of the Russian Federation", Novorossiysk, Russia \\ ${ }^{3}$ Federal State Budgetary Educational Institution of Higher Education "Admiral F.F. Ushakov State Maritime \\ University," Transport College, Novorossiysk, Russia \\ ${ }^{4}$ Federal State Budgetary Educational Institution of Higher Education «Kuban State University», Novorossiysk, \\ Russia \\ *Email: petrakova_1984@list.ru
}

\begin{abstract}
The article deals with the specifics of person identification processes in the conditions of social systems functioning. The author notes that identification is a social action, the purpose of which is to establish the identity between a person and individual qualities of objects of the social environment. The purpose of identification is the individual's adaptation to the social environment by adopting social norms, rules, principles, cultural patterns as their own and socially necessary. The identification process of a person existing within social systems as their subsystem must be considered in terms of social dynamics. Identification is required for a person to adapt to society successfully and for the system itself to reproduce its functioning norms, rules, and principles. In the context of digital transformation and expansion of the social communication system, we can talk about changes in identification processes and, accordingly, in its results. In particular, global integration processes, made possible by the introduction of technical and technological innovations, provide excellent opportunities for intervention in the identification processes to transform the identification bases of the individual. As a result, identification dominants associated with national history, culture, values, gender identity, and other characteristics positioned as authentic are often replaced, however, directly actualised by so-called identification trends promoted through modern mass media, especially on the Internet.
\end{abstract}

Keywords: Identification, Personality, Social system, Social statics, Social dynamics, Cultural patterns, Identification trends.

\section{INTRODUCTION}

The issues of personal identification and selfidentification have always been significant for science and practice. This fact confirms the researchers' appeal to the problem of establishing identity since the time of Greco-Roman antiquity. However, the actualisation of the subject under consideration in modern times is due to several reasons. First of all, identification and selfidentification perform the fundamental function of individuals' awareness of themselves and their place and destination in the modern social system. In addition, identification processes make it possible to determine oneself and others as carriers of specific cultural patterns inherent in individual social communities at a particular stage of their historical development. Today, the identification problem takes on a slightly different sound since the identification process takes place in conditions of continuous expansion of the system of social communications. Modern man is constantly at the 
intersection of various information flows, being at the same time a carrier of meanings, a subject, an object and a means of their transmission. The identification basis of each personality is continuously being strongly influenced by new determinants propagated by communication channels and generated by numerous and diverse communication initiators. Moreover, under the most robust information onslaught, many identification values turn from constants that determine the essential elements of identity (nationality, gender, etc.) into variables, thereby losing their fundamental inviolability.

\section{MATERIALS AND METHODS}

Many researchers in social philosophy and sociology have been engaged in developing problems of identity identification and manipulation of consciousness. The primary theoretical basis for the development of the research topic was the works on the structural and functional theory of T. Parsons [1, pp. 41-48], the theory of social communication (J. Habermas [2, pp. 229-230], N. Luhmann [3, pp. 45-48], P. Bourdieu [4, pp. 92-96], etc.), as well as on the problem of manipulation of public consciousness with the help of mass media (W. Lippman [5, p. 34-39], G. Debord [6, pp. 23-24], etc.).

The theoretical and methodological basis of the study is due to the complexity of its object and subject and is characterised by extensive coverage of the ideas available in social philosophy and sociology about the specifics of the functioning of an individual in conditions of constant changes in the communication environment.

The study was carried out based on the following methods:

- descriptive, used in the presentation of the prominent positions on the issue under consideration;

- comparative analysis and synthesis used in the comparison and generalisation of points of view on the problem of the implementation of identification processes in conditions of constant social changes associated with the expansion of the sphere of social communications caused by transformations in the digital sphere;

- a systematic approach that allowed us to consider the issues of manipulative intervention in the processes of personal identity formation comprehensively.

\section{RESULTS}

\subsection{Personal identification as a condition for the functioning of the social system}

The processes of identification and selfidentification of a person are directly related to the being context in which an individual exists. Since its habitat is mainly society, it seems appropriate to consider the issues of identity formation, considering the relationships that arise in social systems.

The social system is an empirical system, as $\mathrm{T}$. Parsons points out. It is a set of interrelated elements individuals interacting with each other and in this interaction forming a single whole - society. In the social system, with the complication of social relations, social structures arise associated with the allocation of classes, layers, etc. [1, pp. 45-46; 7, p. 16; 8, pp. 109110] In addition, in social systems, as forms of social interactions develop, differentiations caused by functional features arise. This phenomenon is associated with the emergence of social institutions that ensure the activity of various subsystems and, accordingly, spheres of public life.

Identification is a social action that promotes the establishment of identity between a person and subsystems with their signs and properties, in which he is simultaneously included. Identification serves to adapt the individual to the social conditions of existence, assimilate the principles of the functioning of the system and the nature of the interaction of its elements (subsystems, social structures, social institutions, individuals).

For a more accurate consideration of the identification processes that a person implements, being part of a social system, let us turn to the classification of subsystems of $\mathrm{T}$. Parsons. The first is a personality system, self-identification in which presupposes an awareness of oneself as an integral entity with a set of characteristics of the organism that are in constant interaction with each other. The second is social, where the personality appears to be part of a more complex social organism and is in continuous interaction with other individuals. The third is cultural. It implies that aspect of social interaction in which the exchange of values and meanings, the transfer of experience, realising the reproduction of social ties and relationships, is carried out. When considering this system, the most significant in the identification processes T. Parsons calls the preservation and interpenetration of ideas and ideas, providing an entire community of individuals. In other words, in the aspect of the cultural system, identification is considered as a necessary process of forming a community of ideological concepts of society, thanks to which individuals think of themselves not as separate systems but as systems that are in constant interaction with their kind since they are united by universal grounds of belonging to a common historical past, norms, traditions, values developed in it, and potential opportunities for joint construction of the future. It is the cultural principle of every social system, as postulated by T. Parsons, allows to speak not about the individual, 
but about the personality, where the latter is "that aspect of the living individual as an "actor", which should be understood in terms of the cultural and social content of the learned patterns that form his behavioural system" [1, p. 41]. To be noted that describing the social nature of identity, sociologist T. Parsons does not detract from the importance of a person as a biological organism since it is his physical nature that makes all other interactions possible.

The processes of identification of a person, which from the point of view of structural functionalism is also a social subsystem, should be considered in close relationship with social statics, in which elements of a social organism coexist together, and social dynamics, showing how these very elements change each other in the process of interaction, as well as the conditions and directions of this interaction. In turn, we understand social dynamics as an evolutionary development, which is possible due to the interaction of elements within the system and communication with the external environment. The evolutionary transformations made possible the cultural diversity and the complexity of the forms of interaction of the social system elements [8, pp. 409-410]. Accordingly, the change and complication of social life forms lead to changes in identification processes. In this case, the latter is considered as a means of adapting the personality to the environment and the processes in which it is included. A.R. Radcliffe-Brown, like T. Parsons, is inclined to consider social structures and personality as their element in the context of the continuity of life. I.e. the determining value is not a specific personality in a particular version of the social structure considered in statics, but a personality in general, which is influenced by the evolution of the social system and changes in its subsystems caused by interaction inside and outside the system [7, p. 17.].

It should be noted that society is a collection of individuals united by common identification grounds but still have not lost the individual uniqueness of their members, given by nature. That is why it is not necessary to belittle the importance of the biological and psychological nature of the individual, which allows her to initiate the identification process herself and, perceiving cultural patterns, to refract them concerning herself every time in a unique way. In this regard, it is worth agreeing with R. Linton, who points out that "the personality, even of a small child, by the time of its study, already has a kind of psychological warehouse and innate biologically determined inclinations" $[9, \mathrm{p}$. 175].

Regarding the initiation of identity establishment processes, we consider it necessary to adhere to the positions of conceptualism, in which identification is a process of adaptation of the individual to the environment, which is equally essential for both the individual and society and, therefore, both designated subjects interact in this process.

Thus, personality and society are conceived by analogy with the concept of T. Parsons as open systems actively interacting with the environment. Identification is, first of all, a social action aimed at finding and establishing an identity between a person and the qualities of objects of the social system within which a person exists. Consequently, the personality is the subject of activity and, at the same time, the subject of identification since it is the personality that carries out the process of identification itself, although the social environment influences it.

\subsection{Personal identification and the phenomenon of social solidarity}

Identification is necessary for a person to meet many needs, among which R. Linton considers the primary needs for emotional response, security, and new experience acquisition [9, pp. 179-181]. In turn, identification is also necessary for the social system since the formation of a sense of belonging to social processes and social solidarity ensures the reproduction of social ties and relationships, allowing the system to function due to, on the one hand, the continuity of cultural traditions. On the other, their evolutionary transformation is influenced by individual practices implemented by members of society. The means of consolidating individual-personal and social needs for identification is the mechanism of socialisation, passing through which an individual adapts and, having adapted, acting within the framework of institutional norms, becomes able to influence the system's state.

It would be appropriate to say that identification as a social action of a person serves the purpose of its entry into society, ensuring satisfaction, nevertheless, of individual needs [9, p. 176]. Identity is formed during socialisation and is a vital source of balanced interaction between individuals and social systems.

Any social system is open in its type. Interaction with the external environment allows you to draw resources from the latter: personal, intellectual, informational, including broadcasting new ways of social organisation. Identification processes in the conditions of functioning of the social system are mainly due to the phenomenon of social solidarity. Even the philosophers of antiquity and the Middle Ages noted that a person is such exclusively in the conditions of society and cannot exist without him $[10$, p. $454 ; 11$, p. 234]. At the same time, social solidarity can also be evaluated ambiguously, since, on the one hand, it ensures collectivisation and compatibility of decisions and actions, on the other hand, it leads to restriction of personal freedom, habituation to a social norm, "the manifestation of individuality in socially acceptable 
variants" [9, p. 185]. In the conditions of technological expansion of the system of social communications, social solidarity is the factor that makes it possible to accept new determinants of behaviour introduced into the mass consciousness, positioned as socially valuable and necessary [12, pp. 95-96]. In such cases, personal rejection of the imposed new social norm in individuals conflicts with the desire for social solidarity, generating fear of being outside the system. "Bloggers with many subscribers, owners of personal pages on social networks with many "friends", owners of websites that are mini-MCT and guides of their owner's ideas, and other actors of the information space become significant others in the modern world. That is, today significant others are, to a greater extent, not people from the immediate environment, but characters from the mass media" [13].

\subsection{Digital transformations as a factor of personal identification}

To be noted that the main factor of identification in the conditions of functioning of social systems is culture. It supports the coherence of public opinion and the behaviour of individuals, forms a cultural pattern, ensures the management of individuals in the process of their life. It also makes public behaviour predictable due to stereotyping, gives a sense of stability, since in most cases, a person knows what to do and how to do it, transforms individual behaviour into a typical one and ensures the preservation of the social system. The source of cultural patterns is experience. Cultural patterns introduce individuals to socially-oriented behaviour and show them their social structure. In turn, the system of ideas, views, transformed into an ideology, forms a personal worldview that determines the corresponding behavioural acts. Thus, citizenship, patriotism as system-forming ideological cores presuppose the emergence of a sense of unity with the Motherland in individuals through a sense of belonging to the historical and cultural past and initiate the desire to build a joint future through activities in the present. At the same time, the translation of cultural patterns in the context of the functioning of the information society and the ongoing global cultural integration is, on the one hand, a controlled process, on the other hand, a systemforming one in the formation of new bases of identity.

A good example is a Russian society functioning in pandemic conditions. In particular, since the first lockdown in 2019, a parade dedicated to the next anniversary of the victory of the Soviet people over the Nazi invaders has not been held in our country. At the same time, there is practically no advertising of new cinema products of domestic production dedicated to the theme of the Great Patriotic War. Since 2019, the subject of television broadcasts of federal channels has also changed during the celebration of Victory Day: in particular, the minimum time on the air is occupied by military-themed programs and films. The trend set by the federal centre is being successfully implemented locally. In educational organisations, events dedicated to the memorable dates of the Great Patriotic War are more formal than meaningful. Many creative contests that had previously been massive have been cancelled or switched to digital format and thus have lost their powerful impact effect. So, poems or songs about the war, read or sung in the audience, listened to online, no longer cause a strong emotional response. The study of history from the discussion, analysis, search, and comprehension of historical facts has turned into the assimilation of algorithms for passing the Basic State Exam, Unified State Exam, writing All-Russian tests. In other words, the idea of national identity, conditioned by a common historical memory and historically developed behavioural models that allow this very memory to be preserved and form a sense of belonging to its history and culture in the minds of the younger generation of Russian society, is losing its primary importance. At the same time, the expansion of the mass communication system through the popularisation of social networks, the emergence of new Internet channels allows, using modern technological possibilities of digitalisation, to fill the vacuum formed by other identification determinants that are not related to the national idea in any way.

Identification in the conditions of social systems functioning is a necessary, inevitable and, at the same time, manageable process. According to P. Bourdieu, the social space in which a person functions and carries out identification processes is determined by the "structure of capital and profit distribution", and therefore is a "place of struggle" [4, p. 19]. In other words, one of the grounds for identification in a dynamically changing social system is social status, prestige, determined by professional affiliation, income, nature and volume of consumption. In addition to the above, in the conditions of technological shifts in the system of social communication, which gave rise to global integration processes and numerous valuesemantic transformations, a person often becomes an object of social management or manipulation, as a result of which the identification grounds collapse, are transformed or replaced by others. The modern individual is actively involved in mass communication, mainly through Internet technologies. Being at the intersection of many information flows simultaneously, a person becomes incapable of a holistic perception of reality; his picture of reality is eclectic, mosaic. Moreover, communication transmitting contradictory information is carried out so intensively that the individual does not have time to compare, compare, analyse, as a result of which the probability of successful introduction into the consciousness of the 
identification constructs necessary for the initiator of manipulation increases significantly [14, p. 919].

In addition to the above, it should be noted that the expansion of the individual's communication system, one way or another, entails the transformation of identification grounds. Especially the identification processes are influenced by the social reality that exists "here and now". In this sense, virtual and augmented reality technologies that create the effect of presence and involvement, as well as countless noise messages, on the one hand, disorientate, not allowing to distinguish between the real and unreal, meaningful and unimportant, true and false, on the other hand, make it possible to construct an identity, embedding new identification dominants into it every time [15, p. 20]. The intensification of social processes in the social system generates changes in the value-semantic field. And the extensive capabilities of a technically and technologically developed information interaction system allow replacing or transforming the basic elements of identity so quickly that the individual himself does not have time to realise himself as a carrier of an "updated" identity. As a result, trends become the fundamental foundations of identification. For example, it has become fashionable, especially among young people, to identify themselves with a person of nontraditional sexual orientation in recent years. Today, "the average age of sexual debut is 17.7 years... The younger generation realises and accepts their sexual orientation earlier... The demographic shift may be associated with an increasingly tolerant attitude among young people" [16, p. 83; 17, pp. 449-454]. Probably, this is facilitated mainly by the spread of Western cinema products, where same-sex relationships are positioned as the norm. Today, in the context of global cultural integration, there is a rethinking of "gender patterns", and sexual orientation largely becomes the result of "correlating one's individual parameters/desires with cultural models" [18, p. 23]. Another trend of identification has become the artificial construction of one's own identity on the web, including choosing a visual image, forming a personal portrait of traits not inherent in a real person. Today it has become fashionable to be popular, regardless of the reasons for popularity, to be financially successful without considering education, etc. All these examples show that, firstly, technological transformations in social communication have entailed dynamic changes in the processes of establishing identity. Secondly, the identification processes are actively influenced by manipulation, which allows identity elements to be destroyed, transformed and replaced. It is challenging to resist these influences in conditions of constant intensification of the information flow.

\section{CONCLUSIONS}

Summing up, it should be noted that identification is the establishment of identity between a person and a social system or its elements. The purpose of identification is, on the one hand, the social adaptation of the individual through the assimilation of sociocultural patterns, norms, values; on the other hand, the individual's awareness of himself as a part of society due to the commonality of various social characteristics (gender, age, professional affiliation, nationality, worldview, etc.).

In the context of social systems theory, a personality is a system in itself since it has an ordered set of interrelated characteristics that determine its individuality and is an element of a more complex social system, acting as a carrier of cultural patterns.

The process of identification in the conditions of society also has the property of consistency since, in the course of its implementation, there are processes of search, analysis, comparison, comparison and recognition of identification elements inherent in the individual and the social system. Identification, even conditionally, to study it through social modelling cannot be considered without considering the dynamics of social changes. The latter determines the diversity of the content of the identification grounds.

Identification is necessary for both the individual and the social system. Social norms, rules, and forms of social interactions acceptable to society are adopted and assimilated during its implementation. A person, identifying with society, realises himself as part of a more complex and extensive social system, determines his place in the social structure and, based on this, implements socially acceptable behaviours. In other words, identification serves to organise information about oneself and others and design possible social action trajectories. At the same time, the implementation of identification allows the system itself to function since it ensures the norm determines the behaviour of its elements.

Identification is conditioned by the needs of the individual to feel his belonging to society. At the same time, through the desire of individuals for social solidarity in the conditions of functioning of social systems, it becomes possible not only to assimilate patterns, norms and rules of behaviour but also to change them through the introduction of other sociocultural determinants into the mass consciousness. This becomes especially evident in the expansion of the system of social communications through the development of information technologies. The social system functioning in the conditions of modern Russia is characterised by openness and an almost complete absence of consolidated social control. Information flows in it are messy and numerous. Their chaotic 
continuous movement leads to the destruction of the integral identity basis of the personality, to uncertainty in the value-semantic field, disorienting the personality and forming an eclectic image of the Self, in which the significant identification variables are not nationalcultural patterns dating back to historical origins, but artificially created and fashionable ideas.

\section{REFERENCES}

[1] T. Parsons, Social Systems, Questions of Social Theory 2 (2008) 38-71.

[2] J. Habermas, Theory of Communicative Action, Questions of Social Theory 1(1) (2007) 229-245.

[3] N. Luhmann, Society as a social system, Moscow: Logos, 2004, 232 p.

[4] P. Bourdieu, Sociology of social space, Moscow: Institute of Experimental Sociology; St. Petersburg: Aleteya, 2007, 288 p.

[5] W. Lippmann, Public Opinion, New York, Harcourt, Brace and Company, 1922, 449 p.

[6] Guy Debord, Performance Society, Moscow, Logos, 2000, 184 p.

[7] A.R. Radcliffe-Brown, Structure and function in a primitive society, London, Cohen \& West, 1952, $240 \mathrm{p}$.

[8] H. Spencer, Social Statics, Kyiv, Gamma Print, 2013, 496 p.

[9] R. Linton, Personality, culture and society, Questions of Social Theory 1(1) (2007) 175-190.

[10] Aristotle, Works: in 4 volumes, M., Thought 4 (1983) 376-644.

[11] Thomas Aquinas, About the rule of sovereigns, Political structures of the feudal era in Western Europe of the VI-XVII centuries, L., Nauka, 1990.

[12] W. Schulz, Reconstructing mediatisation as an analytical concept, European Journal of Communication 19(1) (2004) 87-101.

[13] R.A. Zakharkin, Significant others in the process of secondary socialisation (communication aspect) [Znachimye drugie $\mathrm{v}$ processe vtorichnoj socializacii (kommunikacionnyj aspekt)], Theory and Practice of Social Development [Teoriya $\mathrm{i}$ praktika obshchestvennogo razvitiya], No. 4, 2016. Retrieved from: http://teoriapractica.ru/rus/files/arhiv_zhurnala/2016/4/sociolo gy/zakharkin.pdf

[14] A.S. Petrakova, T.G. Martseva, I.N. Voblaya, E.N. Seifieva, The Problem of Manipulative Interference in the Processes of Identification and
Self-identification of an Individual in the Conditions of the Information Society Functioning, Lecture Notes in Networks and Systems, Springer Nature Switzerland AG 129 LNNS (2020) 915924. DOI: https://doi.org/10.1007/978-3-03047945-9 98

[15] Nath, Hiranya, The Information Society. Space and Culture, India 4 (2017) 19-28. DOI: https://doi.org/10.20896/saci.v4i3.248

[16] D.S. Tolkachev, Features of sexual orientation research: Demographic characteristics of Russian homosexuals [Osobennosti issledovanij seksual'noj orientacii: demograficheskie harakteristiki rossijskih gomoseksualistov], Demographic Review [Demograficheskoe obozrenie] 8(3) (2021) 74-95.

[17] D. Tolkachev, T. Tolordava, Shared Past, Different Future? Russian and Georgian Authorities' Discourse Concerning Homosexuality, Sexuality \& Culture 24(2) (2020) 447-464. DOI: https://doi.org/10.1007/s12119-019-09688-2

[18] D.D. Isaev, Deconstruction of a heteronormative matrix [Dekonstrukciya geteronormativnoj matricy], Journal of the Higher School of Economics [Zhurnal Vysshej shkoly ekonomiki] 13(1) (2016) 9-26. 